\title{
Mode Choice Behaviour Analysis and Exploring Public Preferences for Introducing Bicycle: A Case Study in Rajshahi City
}

\author{
Akanda Md. Raihan Gafur ${ }^{1}$, , Sabrina Sharmin ${ }^{1}$, Sherazum Monira ${ }^{1}$, Hossain Mohiuddin², \\ Nazia Hossain ${ }^{2}$ \\ ${ }^{1}$ Department of Urban and Regional Planning, Rajshahi University of Engineering and Technology, Rajshahi, Bangladesh \\ ${ }^{2}$ Department of Urban and Regional Planning, Bangladesh University of Engineering and Technology, Dhaka, Bangladesh
}

\section{Email address:}

raihanruet12@gmail.com (A. Md. R. Gafur), sabrina.sharminurp@gmail.com (S. Sharmin), anandi.shiraji@gmail.com (S. Monira), hossain.mohiuddin19@gmail.com (H. Mohiuddin), naziasarjil.09@gmail.com (N. Hossain)

${ }^{*}$ Corresponding author

\section{To cite this article:}

Akanda Md. Raihan Gafur, Sabrina Sharmin, Sherazum Monira, Hossain Mohiuddin, Nazia Hossain. Mode Choice Behaviour Analysis and Exploring Public Preferences for Introducing Bicycle: A Case Study in Rajshahi City. International Journal of Transportation Engineering and Technology. Vol. 3, No. 4, 2017, pp. 53-61. doi: 10.11648/j.ijtet.20170304.12

Received: August 20, 2017; Accepted: October 8, 2017; Published: November 23, 2017

\begin{abstract}
In public transport planning and management system, mode choice behavior analysis of the people is an important element. Public demand and preferences for different modes of travel can be identified through it. This paper gives a detail description about mode choice behavior of the people for the selected para-transit modes like rickshaw, auto-rickshaw, cycle and Emma. This also aims to explore public preference for using bicycle over other para-transit modes in Rajshahi city of Bangladesh. Bicycle is an environmental friendly vehicle. As a mode of transportation bicycle has many advantages for cyclists as well as society as a whole. Primary and secondary data was collected for analyzing some factors regarding the particular mode choice. Primary data was collected through household survey, Origin-Destination survey and stated preference survey. Household survey is used for demographic information, O-D survey is used for making trip diary and stated preference survey is used for taking public preference for introducing bicycle. Questionnaire survey has been conducted in the selected locations named Talaimari, Sheroil and Shaheb Bazar in Rajshahi city. Microsoft Excel software is used for some simple statistical data analysis and SPSS software is used for multinomial logistic analysis. A total of five variables were considered in the model estimation of which are quantitative such as Travel cost, Access time, Egress time, Waiting time and In-Vehicle time. From the analysis it is found that the utility and probability for using bicycle is higher among the various modes of transportation. It is also found that people demand bicycle infrastructure such as bicycle lane, secure parking, improved connection, better intersection etc. for safe and comfortable cycling system. The findings indicate that the majority of the people prefers to use bicycle for travelling. So, it is evaluated that bicycling can be introduced in Rajshahi city if all needed facilities are given for the cyclists.
\end{abstract}

Keywords: Bicycling, Bicycle Infrastructure, Public Preference, Multinomial Logistic Model

\section{Introduction}

Generally, in the developing countries, transportation problem, social growth, economic growth, health, and environment are categories that receive the most attention. In case of solving transportation, problem bicycle can play a great role both environmentally and economically [1].
According to the study of, cycling is economically and environmentally beneficial as it is a low-cost, lowpolluting alternative. Bicycle also makes efficient use of limited roadway capacity and it is also an important mode of getting places that are too long for walking. As a means 
of transportation, bicycling is beneficial to the bicyclist as well as to the community as a whole. Introducing bicycle as a traveling mode can ensure more safety and reasonable expense which helps to reach a desirable social goal [2]. In Rajshahi city people use different modes of transport like Auto-rickshaw, rickshaw, emma (It is the local name in Bangladesh but it is also called human holler). But auto-rickshaw is increasing in an unplanned way and it has also a safety problem. People prefer bicycle as for daily traveling but there are some constraints for using a bicycle in the city. Many studies have been found in different countries on such issues but for the first time in Bangladesh, cycle lane construction work has been started by Rajshahi city corporation authority to introduce bicycle in Rajshahi city. People demand bicycle infrastructure such as bicycle lane, bicycle route map, improved connection, better intersection, secure parking etc. The study was conducted to explore public preference for introducing bi-cycle in Rajshahi city. The multinomial logistic model is used to measure the utility and probability for using a bicycle. The analysis is conducted according to some parameter like the age-wise, genderwise, income-wise and occupation-wise preference of the people. Mode choice behavior varies from person to person which depends on a set of factors such as travel cost, travel time, access time, egress time and waiting time. Improved infrastructure such as on-street parking, bicycle lane, street light and other bicycle facilities type and amenities can attract more people to use a bicycle as an efficient mode of daily travel. The finding of the study is divided into the following sections: i) Utility calculation, ii) probability of particular mode choice, iii) Bicycle ownership according to some selected factors, iv) constraints for using a bicycle, v) Improvement schemes supporting bicycle use. The findings of the study can create a scope for future research and its execution can be effectively undertaken by the local authority.

\section{Literature Review}

Mode choice behavior is a fundamental element of travel behavior. It is the most vital stage in transportation planning process and it has a direct impact on the policy-making decisions. Mode choice means the travelers choice of which mode of transport to take (for example easy-bike, rickshaw, human hauler etc.) that individuals or groups of individuals make in selecting the transportation modes that are used for particular types of trips. Using bicycle as an active mode of transportation for daily travel is the biggest issue nowadays. The pool of possible determinants such as infrastructures issues, traffic safety issues, health benefits, natural environmental impacts, socioeconomic factors and end of trip facilities like showers, lockers etc. are influencing to use a bicycle as an active mode of transportation [3].

Ding \& Zhang (2016) estimated travel behaviors in Nanjing City of China by dividing individual travelers into several groups based on their personal characteristics. They collect travelers' personal information and travel information through a reveal preference (RP) survey and a stated preference (SP) survey. The personal information was collected on the basis of gender, occupation, income, and car ownership, while the travel information includes the mode choice, walking time, waiting time, in-vehicle time, fare, comfort, etc. It was found that the accuracy rate of the mode choice estimation using individual grouping were remarkably higher than that of without grouping. It indicates that the individual grouping improved the travel behavior estimation. Statistical analysis system (SAS) software is widely used for hierarchical clustering analysis and it results that long trips prefer cars. The possible interpretation that the waiting time has a higher effect on the utility is that it is more boring to wait than walk [4].

According to the study of policy-sensitive mode choice analysis in Egypt, income is the most important attribute which affects the mode choice behavior model. Developing advanced Logit discrete choice models with several individuals and mode attributes, it is found that the higher income earners are more likely to use private vehicle than public transport like taxi or bus [5].

According to the another study conducted on multimode choice behavior for the traveler in comprehensive transportation corridor shows that the departure time for long-distance \& short-distance travel has great influence on Passengers travel choice and income, fares and travel distance is the main factors influencing choice behavior [6].

In a study of mode choice behavior, a Multinomial logit model was adopted to analyze mode choice behavior. They selected a village area in Kerala, India. They included walk, bicycle, auto rickshaw, two- wheeler, car, and bus as modal share in which two-wheelers form the major share. The study has explained the mode choice behavior of rural residents based on activity based approach. The study shows that People who have no four wheeler ownership, has a negative influence on choosing four wheelers than two wheelers compared to those having four wheeler ownership. The same is the case with choosing three wheelers compared to two wheelers between those without and with three wheeler ownership. It is also found that the variable no license has a positive influence on all modes compared to two wheelers than those who hold a license \& trip duration is having a negative influence on 4 and three wheelers compared to two wheelers. [7].

In a case study on Urban Public Transport Choice Behavior Analysis and Service Improvement Policymaking, the relationships between the cost, time variable and the choice probability of the public transport were analyzed. According to the results, we found that the workability of Multinomial Logit (MNL) Model was better than Nest Logit (NL) model. They used orthogonal design method to generate stated preference questionnaires. Some variables were used to define the utility of the three alternatives and construct the Logistic model. It has analyzed the traveler's choice behavior 
through discrete choices model in Chengdu. The cost, invehicle time, access time and income were the essential factors that have a significant impact on the choice behavior. Some suggestions were provided after quantifying the influence of these factors on the choice possibility of alternative mode [8].

According to the study on gender and used/preferred differences of bicycle routes, parking, intersection signals, and bicycle type " $52.7 \%$ people enjoy cycling in a beautiful surrounding environment $63.7 \%$ men and $69.1 \%$ women were preferring bicycle signals and $53.9 \%$ men and $60.2 \%$ women were preferring cycle tracks in this study". This study was conducted in Hangzhou, China [9].

A research project based on an analysis of Cyclists' Travel Behavior in methodology for locating new routes is focused on infrastructural investment, exploring opportunities for future improvements and providing a guideline to the planners determine optimum locations for future cycling facilities in Montreal, Canada [10].

\section{Objectives and Methodology of the Study}

This paper aimed to assess the mode choice behavior of the people and explore public preference for bi-cycle over existing para-transit modes. Two types of data from both primary and secondary sources were collected for this study. Primary data was collected through the household survey, Origin-Destination survey and stated preference survey. For conducting household survey cluster sampling method is used. Cluster sampling method can be used when the household number is greater than sample size and when the list of elements of the population is not available. The sample clusters are geographically convenient and the clusters are 'natural' in a population. Three selected study area Talaimari, Sheroil and Shaheb Bazar have been chosen for conducting the household survey. The population of Talaimari (ward 25) is 10268, Shaheb Bazar (ward 12) is 9707 and Sheroil (ward 21) is 3475 [11]. Using ' 10 ' as confidence interval and at $95 \%$ confidence level, the calculated sample size is 96 . The household survey is used for demographic information, OD survey is used for making a trip diary and stated preference survey is used for taking public preference for introducing bi-cycle. Multinomial logistic model is used for finding out the utility and probability of selected paratransit mode. Firstly the utility of modes is calculated from the following equation using "SPSS" software. The equation for the utility function is

$$
\mathrm{U}_{\mathrm{k}}=\mathrm{a}_{\mathrm{k}}+\mathrm{a}_{1} \mathrm{x}_{1}+\mathrm{a}_{2} \mathrm{x}_{2}+\mathrm{a}_{3} \mathrm{x}_{3}+\mathrm{a}_{4} \mathrm{x}_{4}+\mathrm{a}_{5} \mathrm{x}_{5}
$$

Where, $\mathrm{U}_{\mathrm{k}}=$ Utility function, $\mathrm{a}_{\mathrm{k}}, \mathrm{a}_{1}, \mathrm{a}_{2}, \mathrm{a}_{3}, \mathrm{a}_{4}, \mathrm{a}_{5}=$ Constant value of Co-efficient and $X_{1}=$ Travel cost, $X_{2}=$ Access time, $\mathrm{X}_{3}=$ Egress time, $\mathrm{X}_{4}=$ Waiting time, $\mathrm{X}_{5}=$ in vehicle time

The equation for probability calculation is:

$$
p(k)=\frac{\mathrm{e}^{U_{k}}}{\sum \mathrm{e}^{U_{x}}}
$$

Here, $\mathrm{P}(\boldsymbol{K})=$ Probability of choosing specific mode $(\mathrm{k})$, $U_{k}=$ Utility function and $U_{x}=$ Individual Utility function The link between equation (i) and equation (ii) is the probability of particular mode should be calculated by utility function [8].

Secondary data includes the information of population which was collected from Bangladesh Bureau of Statistics (BBS).Different kinds of maps of the study area were collected from various sources such as Rajshahi City Corporation, Google earth Image etc.

\section{Study Area}

Rajshahi City Corporation is one of the ten city corporations in Bangladesh. It is the fourth metropolitan city in Bangladesh based on population size. According to the population census, the total population of Rajshahi City Corporation is 449,756 [11]. And the population is increasing here day by day. For the increasing number of population and activities, congestion occurs in several places for different purposes such as educational, commercial and shopping in the area like Shaheb Bazar, Laxmipur more, Courte, Rail station, Rail gate, Newmarket, Talaimari, Kajla and many other areas. It is evident from a field survey in which it can be seen that most congested area is talaimari, Saheb bazar and Sheroil. On the other hand, people move frequently Talaimari, Kajla area as there situated two of the most familiar institutions Rajshahi University of Engineering and Technology and The University of Rajshahi. Besides, there situated many educational institutions in Talaimari, Kajla, Shaheb Bazar area. On the south side of Talaimari, there is Padma River, on the west, there is Shaheb Bazar and on the east there is Kazla. Shahab bazar area is the busiest center place in Rajshahi City Corporation. People visit Shaheb Bazar frequently for educational, commercial and shopping purposes. The main recreational center the Padma garden is placed just beside Shahab bazar.Sheroil is one of the busiest areas in Rajshahi City which is located near Rail Station. This place gets a large extent of business for its surrounding activities. It is bounded on the north by Rajshahi rail station, on the west by Bindur more, on the south by Rajshahi polytechnic institute and on the north by Rajshahi new market. As people visit those places frequently congestion is created most often there. So these three areas are selected as study area. 


\section{Study Area Map}

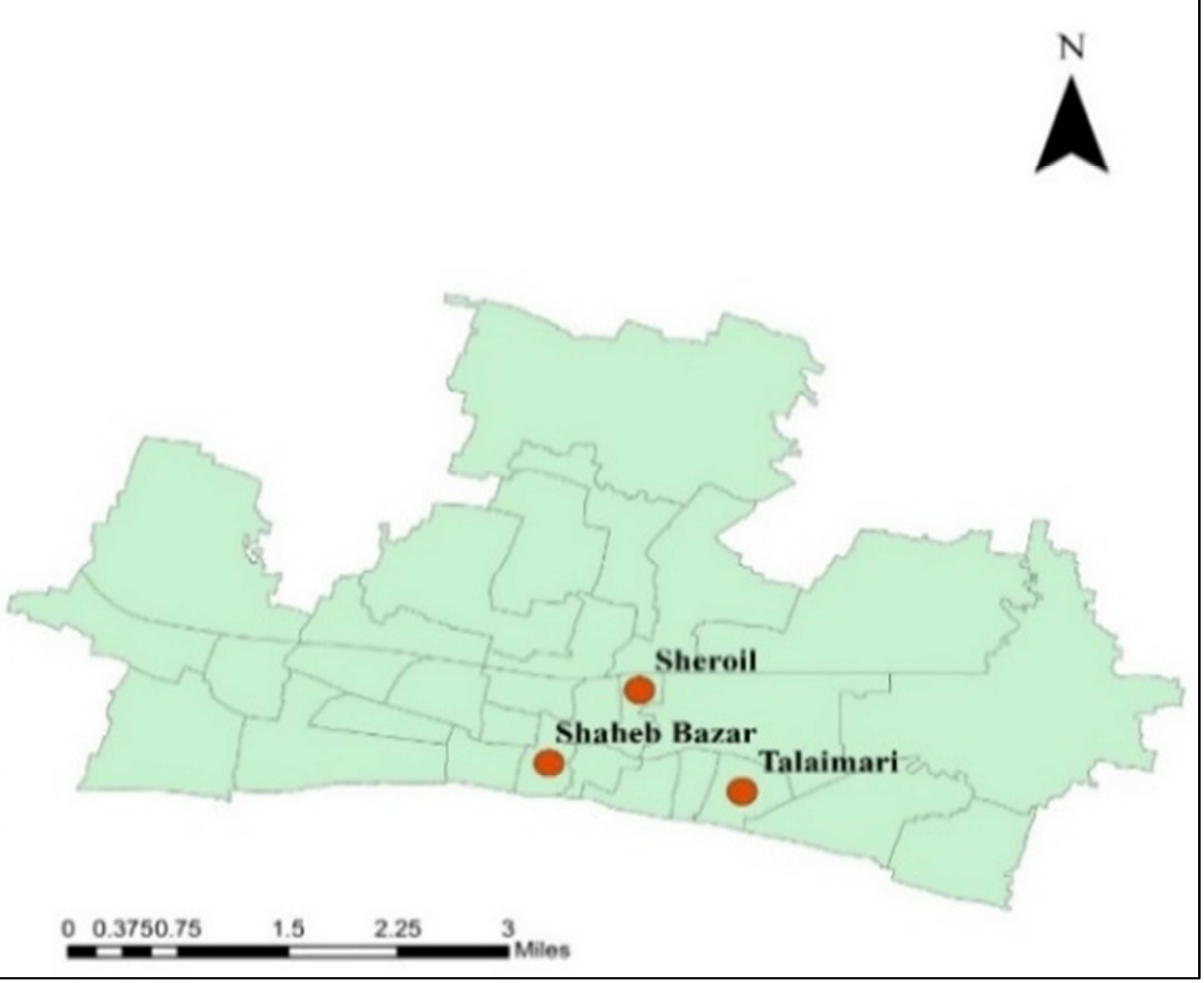

Source: Author's preparation, 2017.

Figure 1. Study Zones of Rajshahi City Corporation.

\section{Model Estimation}

Multinomial logistic model is the most used model in the mode choice behavior analysis. A number of variables are considered for developing equations which measure utility function and the probability of mode choice. In this model, some of the parameters are less significant but the model considers variables which show fitness of good. A multinomial logistic model has been developed for determining the utility of different para-transit modes like auto-rickshaw, rickshaw, Emma, bicycle. The variables used for the logistic analysis is travel cost, access time, egress time, waiting time, in-vehicle time. The model is developed through SPSS (a statistical software package) and estimated by using maximum likelihood (ML) method [12].

$$
\begin{gathered}
U_{\text {auto }}=0.194+(-0.074) X_{1}+(-0.024) X_{2}+0.755 X_{3}+0.063 X_{4} \\
+(-0.044) X_{5} \\
U_{E m m a}=-0.501+0.024 X_{1}+0.059 X_{2}+(-0.022) X_{3}+0.315 X_{4} \\
+(-0.084) X_{5}
\end{gathered}
$$

$$
\begin{gathered}
U_{\text {Rickshaw }}=2.417+(-0.142) X_{1}+(-0.554) X_{2}+(-0.545) X_{3} \\
+0.285 X_{4}+0.084 X_{5} \\
U_{\text {Cycle }}=1.355+0 * X_{1}+0 * X_{2}+0 * X_{3}+0 * X_{4}+(-0.041) X_{5}
\end{gathered}
$$

(variables with zero means there is no travel cost, access time, egress time \& waiting time for bicycle).

In the above equation $X_{1}=$ Travel cost, $X_{2}=$ Access time, $\mathrm{X}_{3}=$ Egress time, $\mathrm{X}_{4}=$ Waiting time, $\mathrm{X}_{5}=$ in vehicle time are the explanatory variables which represent an attribute of the travelers or of the mode considered.

There have been negative $(-)$ and positive $(+)$ sign in the values that estimates the basic test and the impact of the selected variables. The indicative variables such as total travel cost and travel time are generally expected to have a negative coefficient. The coefficient finds out a dependent variable (number of trips) with independent variable (travel cost, travel time) by linear regression. That means with the increase of travel cost and travel time the probability of selecting the particular mode will decrease. 
Table 1. The Multinomial Logistic Model Estimates.

\begin{tabular}{lllll}
\hline Mode & Independent Variable & Co-efficient(B) & Standard Error & Level of Significances \\
\hline \multirow{4}{*}{ Auto Rickshaw } & Constant & 0.194 & 0.387 & .081 \\
& Travel cost & -0.074 & 0.127 & .005 \\
& Access time & -0.024 & 0.103 & .002 \\
& Egress time & 0.755 & 0.147 & .000 \\
& Waiting time & 0.063 & 0.089 & .042 \\
& In vehicle time & -0.044 & 0.191 & .004 \\
Constant & 2.417 & 1.329 & .002 \\
Rickshaw & Travel cost & -0.142 & 0.120 & .001 \\
& Access time & -0.554 & 0.390 & .029 \\
& Egress time & -0.545 & 0.702 & .003 \\
& Waiting time & 0.285 & 0.332 & .056 \\
In vehicle time & 0.084 & 0.427 & .000 \\
Bi-Cycle & Constant & 1.355 & 0.333 & .000 \\
& Travel cost & 0 & 0 & .000 \\
& Access time & 0 & 0 & .000 \\
& Egress time & 0 & 0 & .003 \\
Waiting time & 0 & 0 & .064 \\
Emma & In vehicle time & -0.041 & 0.131 & .003 \\
& Constant & -0.501 & 0.238 & .034 \\
& Travel cost & 0.024 & 0.027 & .067 \\
& Access time & 0.059 & 0.054 & .000 \\
\hline
\end{tabular}

It is evident from the table 1 that the coefficient of travel cost for auto rickshaw and rickshaw is negative. The cost parameter is valid and statistically significant, which means the higher the cost of the certain alternative, the less possibility of alternative is chosen. As there is no travel cost for a bicycle, the high possibility of alternative is chosen.

It is noticeable from the table 1 that that the coefficient of access time for auto rickshaw and rickshaw is negative. The variable of Access time is significant. But Auto rickshaw, Rickshaw, and Emma are not so preferable because of the significant limitations associated with riding on this mode. The level of significance of access time for bicycle $\mathrm{s}$ satisfactory.

It is also shown from the table 1 that the Egress time and Waiting time are generic variables for Auto rickshaw, Rickshaw, and Emma. Accessibility and schedule adherence of the Auto rickshaw, Rickshaw and Emma are good. As bicycle provide door to door services, there is no the Egress time and Waiting time.

Again it is apparent from the table 1 that in-vehicle time is a generic variable of four alternatives. The parameter is statistically insignificant for Rickshaw. Because In vehicle time is generally expected to have negative coefficients. If In vehicle time increase, the probability of selecting the modes will decrease.

\section{Data Analysis and Results}

The utility and probability of particular mode choice are shown by the utility function and probability equation. Four types of para-transit modes (auto-rickshaw, rickshaw, bicycle \&Emma) are selected. Utility and probability for particular mode choice are estimated with the help of different variables and coefficients.

\subsection{Utility Calculation of Existing Para-Transit Modes}

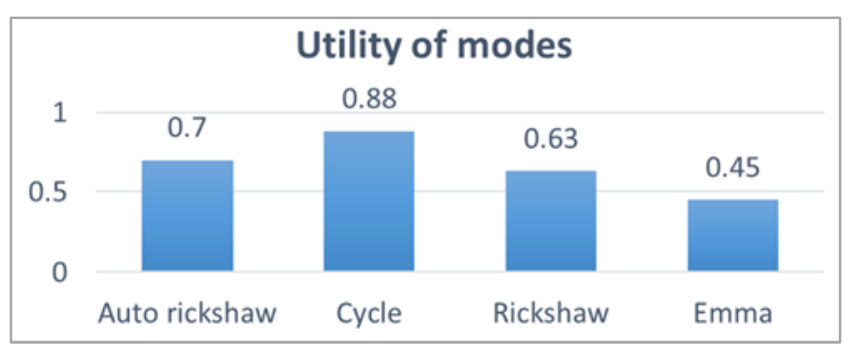

Source: Author's preparation, 2017.

Figure 2. Utility of Selected Para-Transit Modes.

The above chart shows that the calculated utility value is the highest value for cycle than the other modes according to the utility function. The utility of a particular mode is directly proportional to the level of mode choice of that particular mode which depends on the socio-economic characteristics of the individual. In other words, higher the level of choosing a particular mode, higher the utility of that mode. The calculated utility for the cycle is 0.88 and it is the highest among all other existing para-transit modes. The utility service of auto-rickshaw is 0.7 , the utility of rickshaw is 0.63 and Emma have the utility of 0.45 . According to equation (iii, iv, $v$ and vi) the utility function should be calculated number of stages, first of all, find out coefficient of Travel cost, Access time, Egress time, Waiting time, in-vehicle time $\left(a_{1}, a_{2}, a_{3}, a_{4}, a_{5}\right)$ by linear regression in SPSS software, then multiply average $X_{1}=$ Travel cost, $\mathrm{X}_{2}=$ Access time, $\mathrm{X}_{3}=$ Egress time, $\mathrm{X}_{4}=$ Waiting time, $\mathrm{X}_{5}=\mathrm{in}$ vehicle time. 


\subsection{The Probability of Particular Mode Choice}

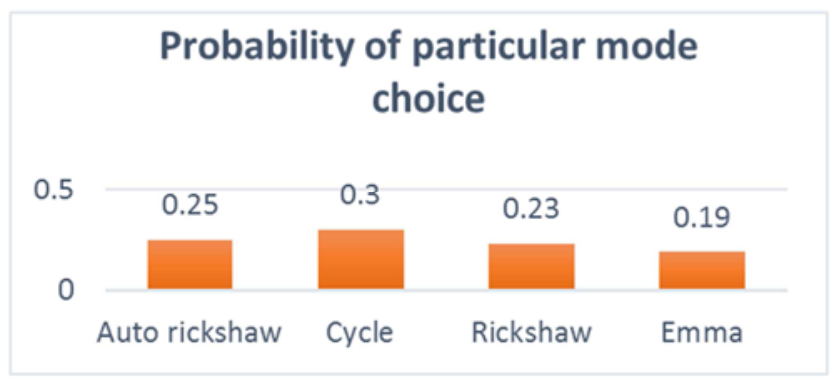

Source: Author's preparation, 2017.

Figure 3. Probability of Particular Mode Choice.

The chart shows that the probability of choosing cycle is higher than other selected modes according to multinomial logistic model. According to the analysis, travel cost, in-vehicle time, access time and individual characteristics have considerable effects on traveler choice behavior, while owning bi-cycle is a significant factor that contributes to the probability of choosing bi-cycle as a favorable mode. Analyzing data it is found the cycle has the highest probability of mode choice $(0.3)$ than other existing para-transit modes according to multinomial logistic model. The probability of mode choice for a rickshaw is 0.23, auto-rickshaw is 0.25 and Emma are 0.19 . Household survey report shows that most of the people prefer to use a bicycle. According to equation (ii), the probability of particular mode should be calculated by a utility function. First of all calculated individual utility function then divided a number of different utility mode $\left(\mathrm{Ua}_{\text {uto }}, \mathrm{U}_{\text {emma }}, \mathrm{U}_{\text {rickshaw }}\right.$ and $\left.\mathrm{U}_{\text {cycle }}\right)$.

\subsection{Exploring Public Preferences for Introducing Bi-cycle}

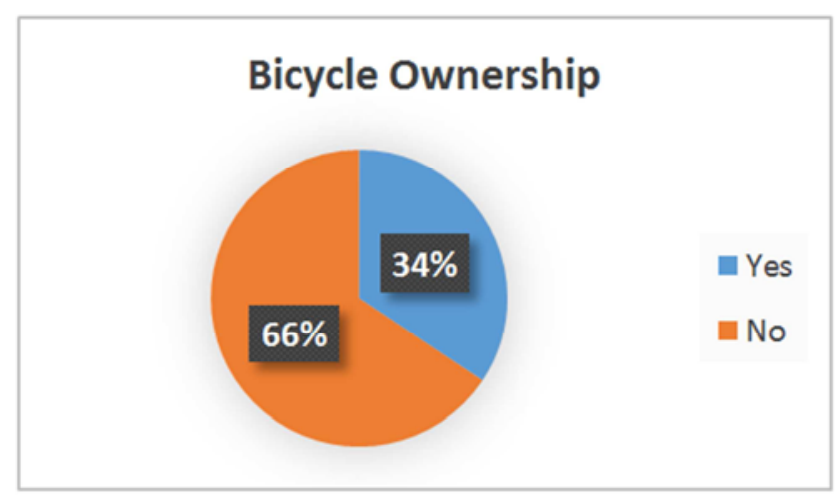

Source: Author's preparation, 2017.

Figure 4. Bicycle Ownership.

The above chart (figures 3) depicts that among 96 samples, $34 \%$ respondents have bi-cycle of their own and the rest $66 \%$ have no bi-cycle because of many problems faces riding a bicycle like lack of accessibility, having no bicycle separate lane in the study area

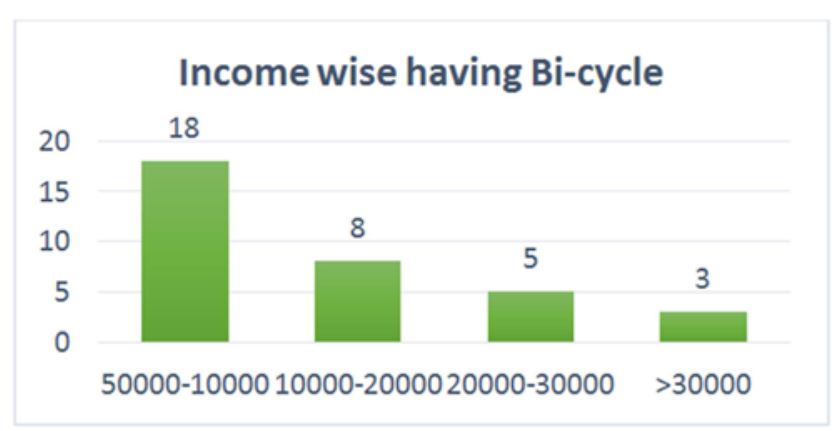

Source: Author's preparation, 2017.

Figure 5. Income Wise Ownership.

The above chart (figures 4) depicts that most of the lowincome people use by-cycle as a major traveling mode. Among 33 bi-cycle owners, 18 people earn 5000-10000 BDT taka per month whereas 8 owners earn 10000-20000 BDT taka, 5 owners earn 20000-30000 BDT taka per month and the rest of the two earn more than 30000 BDT taka. Income is supposed to play a vital role in the determination of the choice of mode. Most of the student and low-income people prefer a bicycle.

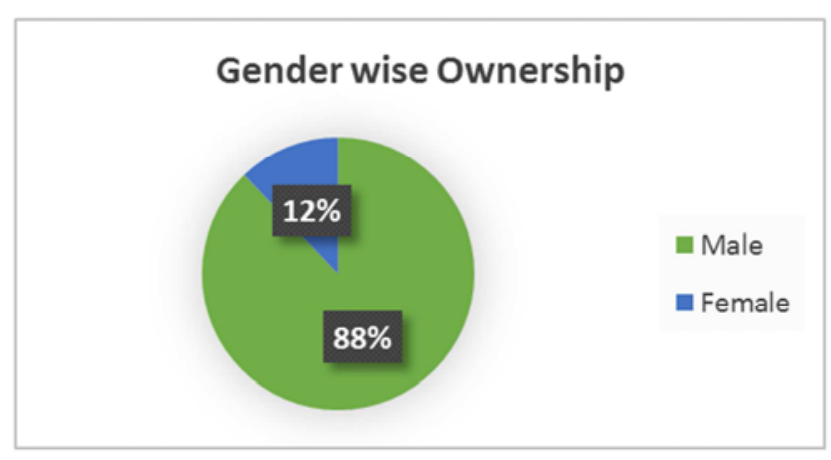

Source: Author's preparation, 2017.

Figure 6. Gender Wise Ownership.

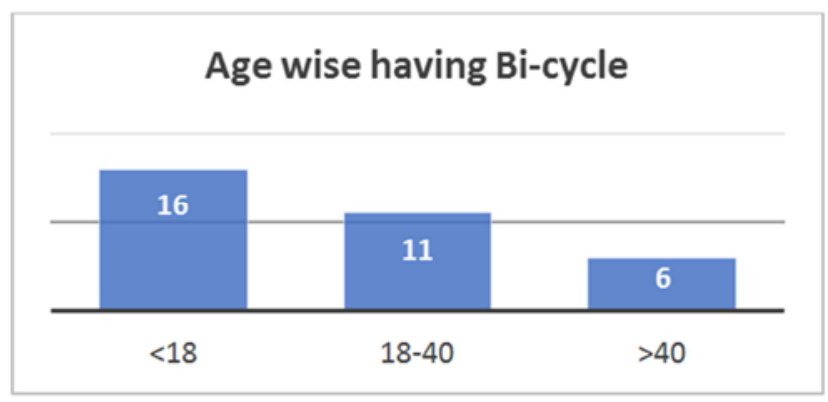

Source: Author's preparation, 2017.

Figure 7. Age-Wise Ownership.

From the figure 5 shows that among 33 bi-cycle ownership, $88 \%$ male have their own cycle and only $12 \%$ female have their own bicycle. Female passengers cannot feel free to ride bicycle, especially in the congested area. Female cannot use bicycle because of many difficulties in riding bi-cycle in the community such as lack of safety in the public roads, congestion, lack of social support etc. Most of 
the male person travel on a bicycle for educational, commercial and shopping purposes.

From the figures 6 it is clearly shown that among 33 bicycle owners, the age of the majority of the respondents (16 owners) is below 18 years who are mainly school-going or college students. The age of 11 bi-cycle owners is between 18 to 40 years old and the age of the rest 6 owners is more than 40 years. As there is no travel cost for a bicycle, students are more likely to use a bicycle. They are therefore more likely to include this mode in choice-sets. Aged people, on the other hand, are less likely to have choice-sets that include a bicycle.

Again in the occupation wise analysis, it is found that among 33 bi-cycle owners, there are 19 students, 5 are businessmen, 3 people are service holder and the rest 6 are from other occupations. Students use bi-cycle most than the people of other occupations.

\subsection{The Purpose for Using a Bicycle}

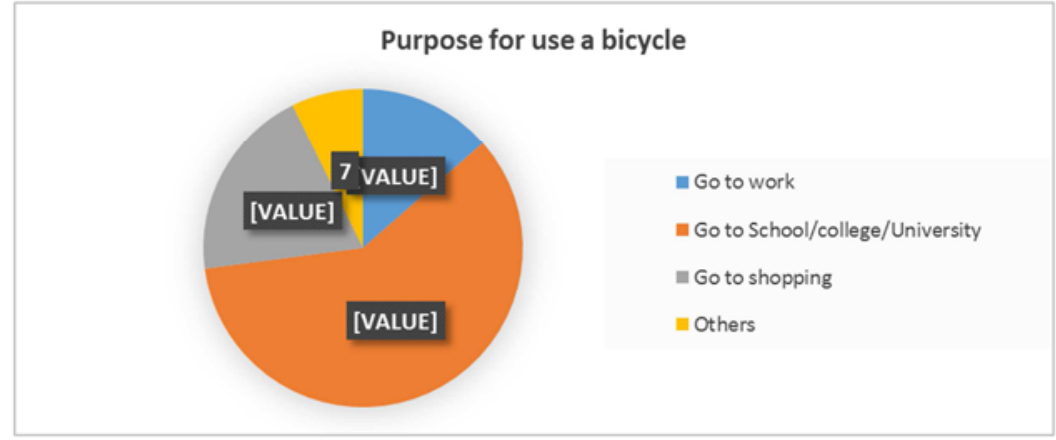

Source: Author's preparation, 2017.

Figure 8. Purpose of Using Bicycle.

The above chart shows that majority of the respondents that is, $57 \%$ respondents use a bicycle for going to school /college/ University because bicycle minimizes travel cost. $13 \%$ respondents use a bicycle to go to their workplace and $19 \%$ use bicycle for going to shopping. Occasionally they use a bicycle to go to exercise or go to the park (7\%).

\subsection{Difficulties for Using a Bicycle}

According to the field survey, it is found that $33 \%$ respondent face difficulties to use a bicycle for having no bicycle lane, $28 \%$ said they can't ride a bicycle, $21 \%$ said that it is very difficult to ride a bicycle on a busy road and $7 \%$ said the roads are too narrow. Unsafe neighborhoods, no street lights are also responsible to create difficulties to ride a bicycle.

\subsection{The Hierarchy for Improvement Schemes Supporting Bi-cycle}

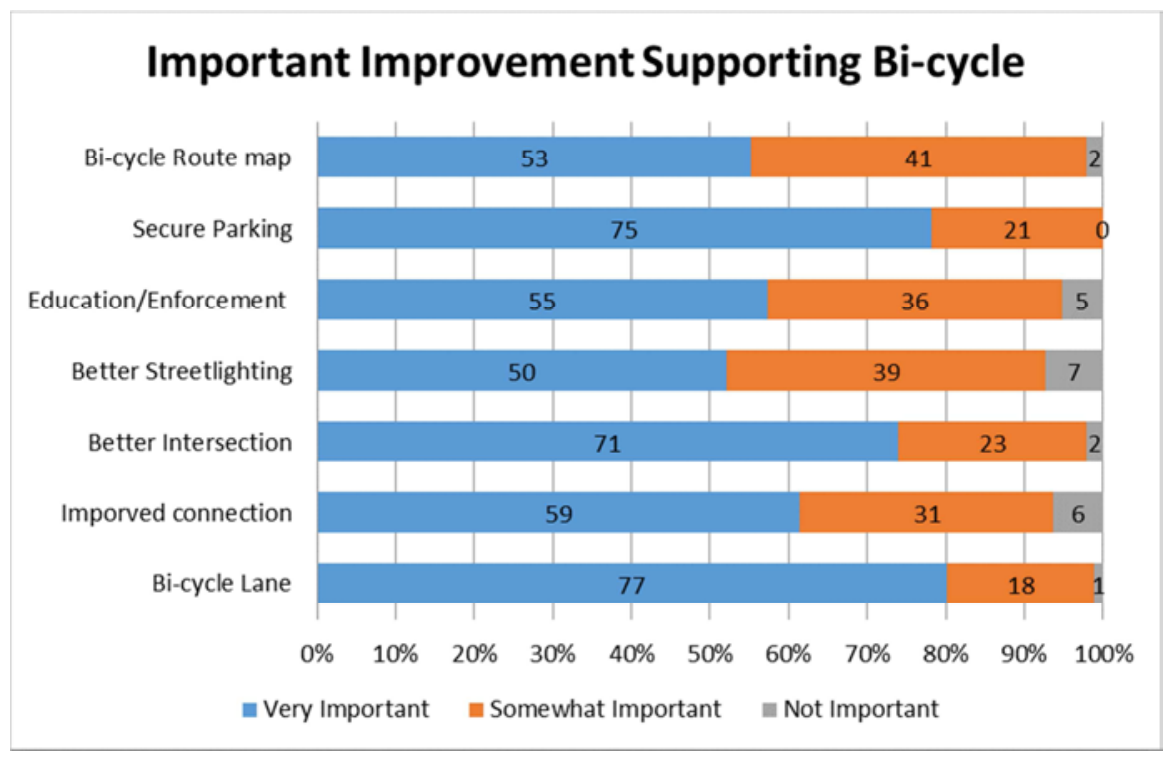

Source: Author's preparation, 2017.

Figure 9. Important Improvement Supporting Bicycle. 
From the above chart, it is clearly shown that among 96 samples, Majority of the respondents (77 respondents) give more emphasize on bicycle lane. Among 96 samples, 75 respondents give priority to secure parking. Among 96 samples 71 respondents give emphasize on the better intersection.

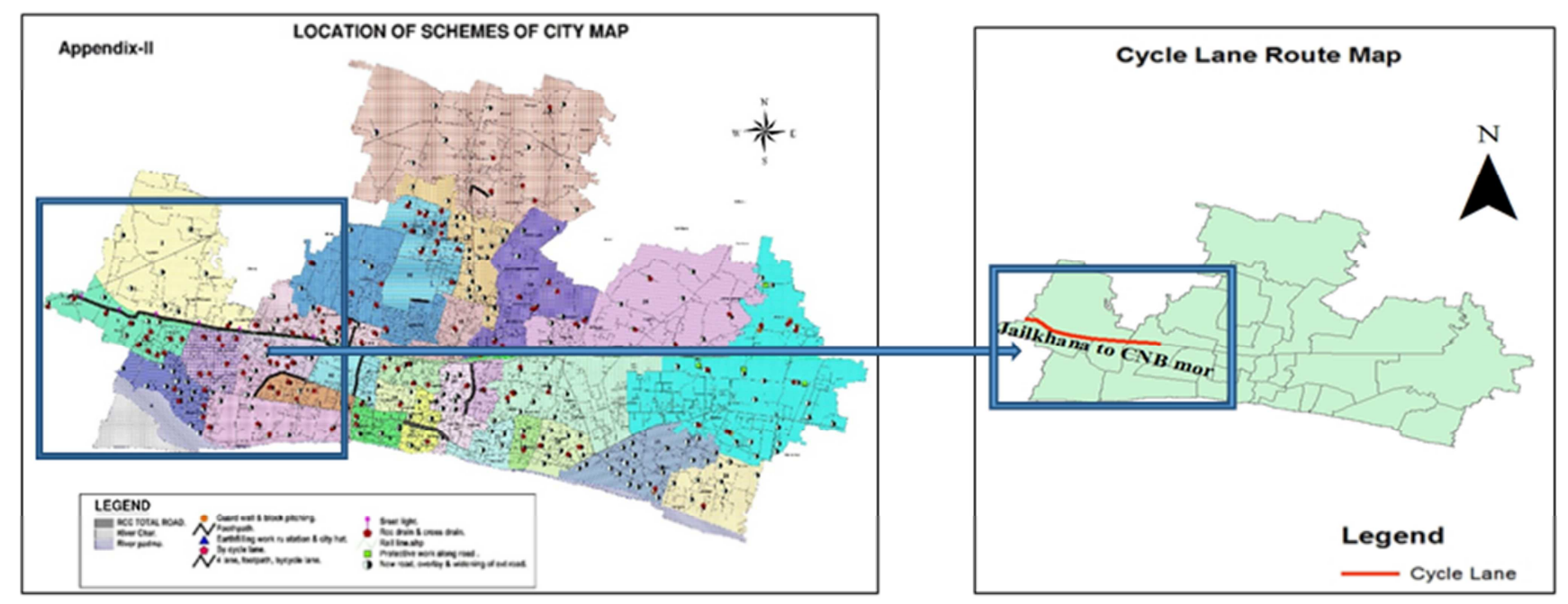

Source: Prepared by Authority of Rajshahi City Corporation, 2016.

Figure 10. Bicycle Lane Route Map.

\section{Recent Work for Constructing Cycle Lane in Rajshahi City}

Recently an approach has been undertaken form Rajshahi City Corporation to construct cycle lane in some selected routes. Already construction work has been started from 2016. A portion of the lane has been constructed on the north side of Rajshahi central jail to CNB more. From the authority of Rajshahi City Corporation, it has come to know that the proposed route length for cycle lane is 300 meter and width of the lane is 10 feet.

In the map, the constructed cycle lane has been indicated. The authority also informs that there is a plan for constructing bicycle lane in the city Bypass, Bil Shimla to Kashiadanga and Bindur more to Talaimari.

\section{Major Findings}

The study was conducted for two purposes: to assess the mode choice behavior of people on existing para-transit modes and to explore public preference for introducing bicycle in Rajshahi city. Four existing para-transit modes (Rickshaw, auto-rickshaw, Emma\& cycle) were chosen for analysis. Using Multinomial Logistic model it is found that the utility and probability of using bi-cycle show the highest value among other existing para-transit modes in Rajshahi city. The utility of cycle is 0.88 , auto-rickshaw 0.7 , rickshaw 0.63 and emma 0.45 . From probability analysis, it is found that the probability of using bi-cycle is 0.3 , auto-rickshaw 0.25 , rickshaw 0.23 and emma 0.19 . Besides, the survey result found a different opinion on using bicycle. The survey was conducted to gather people's preference for introducing bi-cycle. It has also analyzed to conduct age-wise, genderwise, income-wise and occupation-wise analysis which find out a public preference for using a bicycle. It is found that most of the lower income and middle-class people prefer bicycle for daily traveling. It is also found that most of the young people who are school, college or university students prefer bi-cycle most. It is evident in assessing bi-cycle improvements as transportation project priorities which it is found that a much greater level of importance given to building safe places for cycling such as providing separate cycling lane, improvement of the street lighting system, providing secure places for parking cycle and then on expanding bicycle networks. People also suggested some probable bi-cycle routes for their easement of travel. The suggested route for bicycle lanes is Kajla to Shaheb Bazar, Shaheb Bazar to Laxmipur, Laxmipur to Vadra, Vadra to Talaimari, Zero points to Nowdapara.

\section{Conclusion}

Safety and comfort is the most significant criterion for people when they travel. The bicycle is safer than auto rickshaw or other modes. If a secured bicycle lane is provided in the city, people may reduce their reliance on existing modes to travel within the city. The travel cost, invehicle time, access time and income were the essential factors that have a significant impact on the choice behavior. According to the analysis, travel cost, in-vehicle time, access time and individual characteristics have considerable effects on traveler's paratransit choice behavior, while owning a bicycle is a significant factor that contributes to the possibility of choosing the bicycle as a favorable mode. Using Multinomial Logistic model it is found that the utility and probability of using bi-cycle show the highest value 
among other existing para-transit modes in Rajshahi city. So, it is assessed that bicycling can be introduced in Rajshahi city if all needed facilities are given for the cyclists such as more bicycling facilities (bike paths, bike lanes, bike parking racks, lighted areas, safe signals \& intersections) make areas for bicycling safer, bicycle safety education, improve existing facilities, enforce laws governing bicycling, change laws related to bicycling.

\section{References}

[1] MURPHY, Nhora, Barrera;KNOBLAUCH, Richard., "Hispanic Pedestrian and Bicycle Safety,": Report of Focus Group Discussions in Washington, New York, Miami, and Los Angeles, 2004.

[2] HANDY, Susan, L; XING, Yan. Factors correlated with bicycle commuting: a study in six small US Cities. International Journal of Sustainable Transportation, 2011, 5.2, pp. 91-110.

[3] GRIBBLE, Anna; DOUGLAS, Rina., "Transport-Related Determinants That Influence Decisions to Use Cycling as an Active Mode of Transport for Daily Travel. Allen + Clarke, Final report, 24 July 2014.

[4] DING, Ling; ZHANG, Ning. A travel mode choice model using individual grouping based on cluster analysis. Procedia Engineering, 2016, 137,pp. 786-795.

[5] EI-BANY, Ei-Sayed, Marwa; SHAHIN, Mohamed, Mahir; HASHIM, Ibrahim, Hassan; SERAQ, Mohamed, Sadek. Policy sensitve mode choice analysis of Port-Said City, Egypt. Alexandria Engineering, 2014, vol. 53, pp. 891-901.

[6] LI, Xiaowei; TIAN, Xiaoyan; LI, Xiaodong. Multi-mode Choice Behavior for Passenger in Comprehensive Corridor. Procedia Enginnering, 2016, vol. 137, pp. 849 - 857.

[7] PHILIP, Milimol; SREELATHA, prof; GEORGE, Soosan, Dr. Modelling on Mode Choice Behavior of Rural Middle Class Residents - An Activity Based Approach. International Journal of Emerging Technology and Advanced Engineering,, 2013, vol. 3, iss. 7, pp. 150-155.

[8] CHEN, Lin; YANG, Fei; CHENG, Yang; YAO, Zhenxing; ZHANG, Xu. Urban public transport choice behavior analysis and service improvement policy-making: a case study from the metropolitan city, Chengdu, China. Journal of Applied Statistics, 2015, 42(4), pp. 806-816.

[9] LUSK, Anne, C.; WEN, Xu; ZHOU, Lijun. Gender and used/preferred differences of bicycle routes, parking, intersection signals, and bicycle type: Professional middle class preferences in Hangzhou, China. Journal of Transport \& Health, 2014, 1.2, pp.124-133.

[10] LARSEN, Jacob., "Beyond the Bike Lane: An Analysis of Cyclists' Travel Behavior in Montreal \& A Methodology for Locating New Routes.," Master's of Urban Planning, McGill School of Urban Planning, McGill School, 2010.
[11] "BBS". Bangladesh Bureau of Statistics 2011.

[12] VICTORY, Waikhom; AHMED, M., Ali., "Forecasting Paratransit Utility by Using Multinomial Logit Model: A Case Study.," International Journal of Engineering and Technology (IJET), vol. 8, No 5 Oct-Nov 2016. pp. 2193-2198.

\section{Biography}

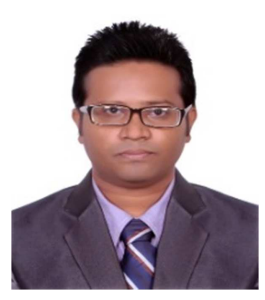

Akanda Md. Raihan Gafur. I am an undergraduate student at Department of Urban and Regional Planning in Rajshahi University of Engineering and Technology (RUET), Rajshahi-6204, Bangladesh. Research Interest: Transportation Planning, Urban Planning.

Sabrina Sharmin. I am undergraduate

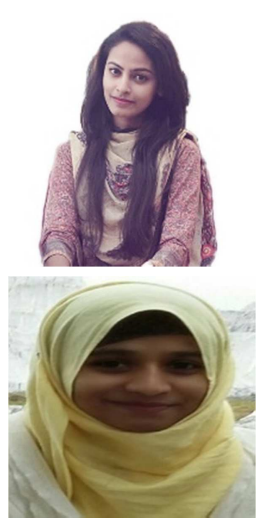
student at Department of Urban and Regional Planning in Rajshahi University of Engineering and Technology (RUET), Rajshahi-6204, Bangladesh. Research Interest: Urban Planning, Transportation Planning.

Sherazum Monira. I am an undergraduate student at Department of Urban and Regional Planning in Rajshahi University of Engineering and Technology (RUET), Rajshahi-6204, Bangladesh. Research Interest: Urban Planning, Transportation Planning.

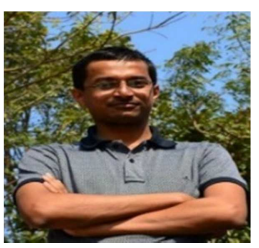

Hossain Mohiuddin. I am presently teaching as a lecturer of Urban and Regional Planning, RUET, Rajshahi-6204, Bangladesh. I did my graduation in Urban and Regional Planning (URP) from Bangladesh University of Engineering and Technology (BUET), Dhaka in 2014. I have also continuing Masters of Urban and Regional Planning (MURP) in the same department from the Lowa university, US. Research Interest: Regional Planning, Transportation Planning.

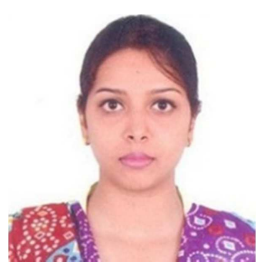

Nazia Hossain. I am presently teaching as a lecturer of Urban and Regional Planning, RUET, Rajshahi-6204, Bangladesh. I did my graduation in Urban and Regional Planning (URP) from Bangladesh University of Engineering and Technology (BUET), Dhaka in 2014. I have also continuing Masters of Urban and Regional Planning (MURP) in the same department from the same university. Research Interest: Disaster Management, Urban Planning. 